Folia Hort. 33(1) (2021): 107-119

DOI: 10.2478/fhort-2021-0008
FOLIA

HorTiculturae

Published by the Polish Society

for Horticultural Science since 1989

\title{
Relationship between salicylic acid and resistance to mite in strawberry
}

\author{
Juliano T. Vilela de Resende ${ }^{1, * \odot}$, Rafael Matos ${ }^{2 \oplus}$, Douglas M. Zeffa ${ }^{3 \oplus}$, \\ Leonel Vinicius Constantino ${ }^{1 \oplus}$, Silas M. Alves ${ }^{1 \oplus}$, Maurício U. Ventura $^{1 \oplus}$, \\ Nathalia C. V. Resende ${ }^{4 \oplus}$, Khamis Youssef ${ }^{5, * \odot}$
}

\footnotetext{
${ }^{1}$ Department of Agronomy, Londrina State University, Londrina, Paraná, Brazil ${ }^{2}$ Department of Agronomy, Midwestern State University, Guarapuava, Paraná, Brazil

${ }^{3}$ Department of Agronomy, Maringá State University, Maringá, Paraná, Brazil ${ }^{4}$ Department of Agronomy, Viçosa Federal University, Viçosa, Minas Gerais, Brazil

${ }^{5}$ Agricultural Researcher Center, Plant Pathology Research Institute, Giza, Egypt
}

\begin{abstract}
The two-spotted spider mite (TSSM) Tetranychus urticae is a polyphagous pest which infests several wild and cultivated species of plants worldwide. To date, this mite is the most deleterious pest attacking the strawberry plant under a protected environment. Exogenously applied salicylic acid (SA) has been found to induce resistance to biotic and abiotic stresses. Morpho-anatomical changes in strawberry leaflets and TSSM preference tests were investigated in response to SA treatment. Plants grown in a greenhouse were foliar sprayed with different concentrations of SA $\left(0 \mathrm{mg} \cdot \mathrm{L}^{-1}, 25 \mathrm{mg} \cdot \mathrm{L}^{-1}\right.$, $50 \mathrm{mg} \cdot \mathrm{L}^{-1}, 75 \mathrm{mg} \cdot \mathrm{L}^{-1}$ and $100 \mathrm{mg} \cdot \mathrm{L}^{-1}$ ). After the third application, certain parameters including the number of glandular and non-glandular trichomes, thickness of leaflet, abaxial cell wall, adaxial cell wall, palisade and lacunous parenchyma and mesophyll were measured using scanning electronic microscopy (SEM). Two-choice and non-choice assays were employed to verify the TSSM preference. Exogenous treatment with SA promoted morpho-anatomical changes in the following parameters, namely: thickness of the leaflets, mesophyll, lacunous and palisade parenchyma, cell wall (abaxial and adaxial) and the number of glandular and non-glandular trichomes in strawberry leaflets. In general, TSSM preferred less leaflets treated with SA compared with the control in a two-choice assay. A lesser number of TSSM eggs and live females were also recorded in leaflets treated with SA compared with the control plants in no-choice assays. The values of the number of eggs and live females correlated negatively with those obtained for the morpho-anatomical traits induced by exogenous SA.
\end{abstract}

Keywords: Fragaria $\times$ ananassa, morpho-anatomical, Tetranychus urticae

\section{INTRODUCTION}

The total area for worldwide strawberry (Fragaria $\times$ ananassa Duch.) harvests is estimated to be about 395,844 ha, which amounts to circa 9,125,913 tons (FAOSTAT, 2019). The striped mite (TSSM) Tetranychus urticae Koch (Acari: Tetranychidae) is a polyphagous pest found on cultivated and uncultivated plants (Osman et al., 2019). So far, TSSM is found to be the most deleterious pest that attacks strawberries in a protected environment all over the world (Esteca et al., 2017; Ong et al., 2018). TSSM causes qualitative and quantitative losses in strawberry production; especially during periods of low rainfall (Dias et al., 2012; Rezaie et al., 2013), TSSM has increased reproductive potential and a decreased life cycle, which leads to an increase

*Corresponding authors.

e-mail: jvresende@uel.br (J.T.V. de Resende)/youssefeladawy@yahoo.com (K. Youssef). 
in the infesting population, and consequently, extensive damage being caused to the commercial crop. Due to increase in the pest population, there is increase in the application of pesticides, which not only promotes the development of pest resistance to phytosanitary treatments, but also increases the damage to the environment and to the health of farmers and consumers (El-Wakeil, 2013; Wang et al., 2018). Moreover, it is well known that pesticides/acaricides have several limitations, generating a biological imbalance and consequently, increasing the costs of production (Koch et al., 2017; Silva et al., 2019). Thus, there is a strong interest in the development of alternative methods of control, which are more sustainable (Lachhab et al., 2015; Youssef et al., 2019).

Under biotic and abiotic stresses, morpho-anatomical changes such as trichome increments are triggered in plants (Figueiredo et al., 2013; Lucini et al., 2015), increasing the thickness of the epidermis and foliar mesophyll, synthesis of crystal waxes, tissue resistance and functioning of substance secreting structures (Tenhaken, 2015; Zhu, 2016).

The synthesis of the volatile methyl salicylate compound (MeSa) is one of the main signs of a plant's response to stresses. Through the release of $\mathrm{MeSa}$, the neighbouring plants are alerted by activating specific genes that are transcribed into proteins that assist in the synthesis of defence structures or substances (Backer et al., 2019; Miller et al., 2017). MeSa is derived from salicylic acid (SA) and is produced through secondary metabolism. SA is found in leaves and other plant parts, and its concentration inside different plant cells is varied (Hayat et al., 2012). Biochemical studies suggest that SA is synthesised from the phenylalanine pathway with benzoate as the immediate precursor (Hayat et al., 2014). However, more recent genetic analyses indicated that the bulk $(>90 \%)$ of SA is synthesised from the isochorismate pathway (Chen et al., 2009). Although the role of plant isochorismate syntheses in SA production has been established, plant enzymes that convert isochorismate into SA have not yet been identified.

The application of exogenous SA in plants promotes increased resistance to pests and diseases that cause extensive damage to commercial crops. In addition, SA can replace/decrease the use of pesticides and/or reduce waste in the final product, increasing profitability and encouraging the approach toward sustainable agriculture (Donovan and Delucia, 2013; Wani et al., 2017). Exogenous SA also provides conditions for plants to overcome situations of abiotic stress, including heat, drought and saline environments (Nazar et al., 2017).

Exogenous SA has been reported to induce resistance to the striped mite in strawberry cultivars, reducing adult survival and oviposition (Favaro et al., 2019). However, the mechanisms related to these resistance effects are not yet fully understood, especially regarding the morpho-agronomic changes that occur in plants attacked by the pest. Thus, knowing these forms of defence that the plant develops can favour the search for more sustainable crops. Given the issues that are discussed above, the objective of this research was to evaluate the effects of exogenous SA on the development of morpho-anatomical defence structures in strawberry plants and the relationship of these structures with the biology and behaviour of T. urticae.

\section{MATERIALS AND METHODS}

\section{Plant materials}

For the test, juvenile strawberry ('Sweet Charlie') plants obtained from the nursery were grown in pots ( $3 \mathrm{dm}^{3}$ per 40 days) containing a mixture of soil and commercial bio-stabilised substrate, obtained by anaerobic digestion in a reactor and fertilised with $3.8 \mathrm{~g}$ NPK formula 4-14-8 (NPK) in an automated greenhouse ( $25 \pm 3^{\circ} \mathrm{C}$, RH $80 \pm 5 \%$, and photoperiod 13:11 h, light:dark). For each treatment, eight plants were taken and divided into four replications with two plants per pot, based on the preliminary research carried out by Favaro et al. (2019).

\section{Spraying SA and TSSM infestation}

Application of SA was initiated 30 days after transplanting. Five concentrations $\left(0 \mathrm{mg} \cdot \mathrm{L}^{-1}\right.$, $25 \mathrm{mg} \cdot \mathrm{L}^{-1}, 50 \mathrm{mg} \cdot \mathrm{L}^{-1}, 75 \mathrm{mg} \cdot \mathrm{L}^{-1}$ and $\left.100 \mathrm{mg} \cdot \mathrm{L}^{-1}\right)$ were applied using an electric sprayer of MTS brand, model Spritz $18^{\circledR}$, with a capacity of $10 \mathrm{~L}$, driven by an electric motor (with a power of $30 \mathrm{~W}$ ) and pressure sensor of the differential type (precision of $2.5 \%$ and response time of $1 \mathrm{~s}$ ). A nozzle model Xr 110.02 was used, with a flat spray with a pressure of $300 \mathrm{kPa}$, a target height of $0.5 \mathrm{~m}$ and a nominal flow of $0.78 \mathrm{~L} \cdot \mathrm{min}^{-1}$. Foliar surfaces were treated until saturation point (dripping). The plants were sprayed with SA at 15 days' time intervals after transplantation, for 5 months. The plots were separated by $3 \mathrm{~m}$ and consisted of two pots with one plant from the pot. After the third application, 60 days after the transplant, 12 adult mites of the same age were released per plant in the proportion of 3 females for each male, in line with Favaro et al. (2019). The doses of SA used in the bioassay were also established by Favaro et al. (2019). Yet, in these trials, it was postulated that infestation with the pest was necessary for plants to respond with morphological changes on application of SA.

\section{Morpho-anatomical assessments}

\section{Quantification of trichomes in leaflets}

Expanded juvenile leaflets were sampled on the upper third of the plants, 45 days after infestation with TSSM. Two leaflets from the plant were removed from each replicate, totalling 16 samples per treatment. From each sample, two paradermic cuts were made on the abaxial and adaxial surfaces of the leaflet with 
a rotating microtome, totalling 32 cuts per treatment. The sampled cut leaflets were fixed with a metallic substrate using carbon tape (Goldstein et al., 1992). The images were captured by SEM (Tescan Vega3 HV $30 \mathrm{kv}$ ) in an area of $300 \mu \mathrm{m}^{2}$ of the leaflet. Trichomes were quantified according to the presence/absence of the glands at the apex of the trichome from 32 images, obtained at the best resolution. The values were determined for each type of trichome (glandular or non-glandular) on the surface of the leaflet (adaxial and abaxial) and weighted to obtain the average of each treatment.

\section{Morpho-anatomical determinations}

For the transverse histological cuts, two leaflets were sampled from a plot (one per plant) collected from four replicates/treatment, totalling eight leaflets. From each leaflet, four paradermic cuts were made on the microtome rotary (MRP2015) with a thickness of $5 \mathrm{~mm}$, totalling 32/treatment. Subsequently, 10 best cuts for capturing images under SEM $(200 \mu \mathrm{m}, 100 \mu \mathrm{m}$ and $50 \mu \mathrm{m}$ of resolution) were selected. Through image analysis, the thickness of the leaflet (LT), abaxial cell wall $(\mathrm{AbCW})$, adaxial cell wall $(\mathrm{AdCW})$, palisade parenchyma (PP) and lacunous parenchyma (LP) of the 10 best images were determined. The values obtained with the measurements of the 10 repetitions were used for statistical analysis and for calculating the averages.

\section{Two-choice bioassay}

At 60 days after the first application, photosynthetically active leaflets were collected from the treatments. Evaluation of the preference of TSSM from plants sprayed with different concentrations of SA was carried out in a controlled environment at the Entomology Laboratory of the State University of Midwest. Leaflets from plants kept in a greenhouse were used as described above. Leaf discs (20 $\mathrm{mm}$ in diameter) from each treatment $\left(25 \mathrm{mg} \cdot \mathrm{L}^{-1}, 50 \mathrm{mg} \cdot \mathrm{L}^{-1}, 75 \mathrm{mg} \cdot \mathrm{L}^{-1}\right.$ and $\left.100 \mathrm{SA} \mathrm{mg} \cdot \mathrm{L}^{-1}\right)$ were compared with the control treatment $\left(0 \mathrm{mg} \mathrm{SA} \cdot \mathrm{L}^{-1}\right)$. The leaf discs were placed side by side in a Petri dish (60 $\mathrm{mm}$ in diameter), connected by a plastic coverslip $2 \mathrm{~cm}$ long and $0.08 \mathrm{~cm}$ wide. A layer of cotton saturated with water was used on the inner base of the Petri dish to prevent dehydration of the leaflet (Figure 1).

The two foliar discs were connected by a plastic coverslip $(18 \times 18 \mathrm{~mm})$ in which six TSSM adult females were released using a fine bristle brush. The females were carefully placed in a medium portion of the coverslip to allow access to both the foliar disks. The Petri dishes were then placed in an environmental chamber $\left(25 \pm 1^{\circ} \mathrm{C} ; 70 \pm 10 \% \mathrm{RH}\right.$ and photoperiod 12:12 h, light:dark) for $24 \mathrm{~h}$. Later, the females in each disc were counted and recorded. The experimental design was a completely randomized design (CRD) with 10 replicates per treatment.

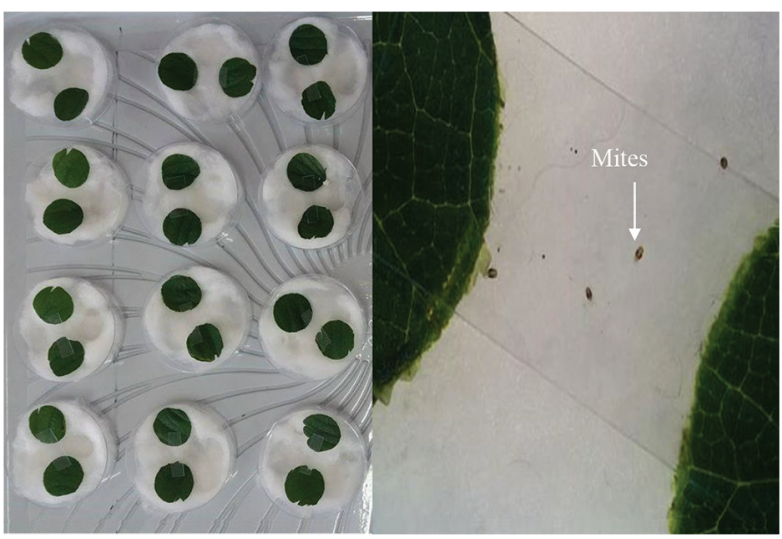

Figure 1. Petri dishes with strawberry leaflets from the cultivar 'Sweet Charlie' for bioassay of two choices with spider mite and female mites arranged on the surface of a coverslip connected to two leaflets.

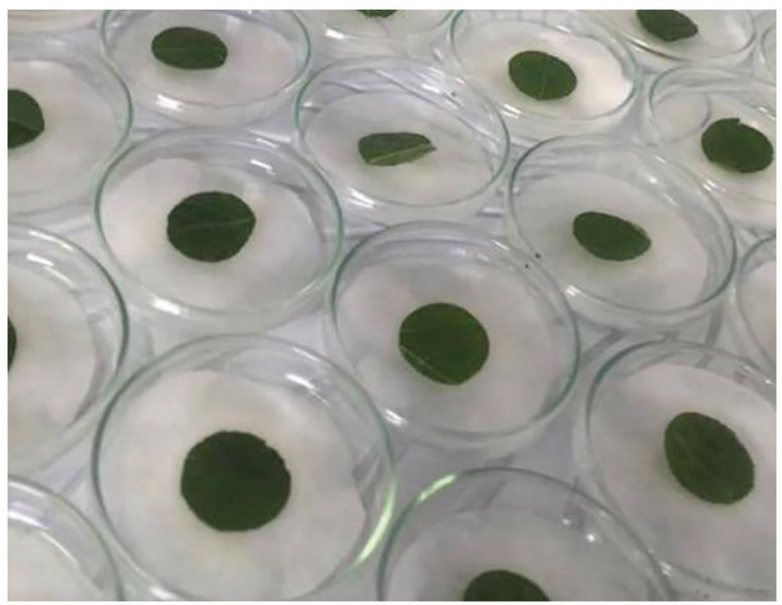

Figure 2. Petri dishes with strawberry leaflets from the cultivar 'Sweet Charlie' to biossay no-choice with the spider mite.

\section{No-choice bioassay}

For the no-choice bioassay, leaf discs $(30 \mathrm{~mm}$ in diameter) from each treatment were used, as mentioned above. A leaf disc was placed in the centre of each Petri dish, on which one female TSSM was released from the controlled creation (Figure 2). The Petri dishes were placed in an environmental chamber $\left(25 \pm 1^{\circ} \mathrm{C}\right.$; $70 \pm 10 \% \mathrm{RH}$ and photoperiod 12:12 h, light:dark). The number of eggs and live adults were counted $24 \mathrm{~h}$ after release (Goldstein et al., 1992). The experimental design was a CRD with 10 replicates per treatment.

\section{Experimental design and statistical analyses}

Normality and homoscedasticity tests were performed on the data obtained. After verifying the assumptions, ANOVA at $p \leq 0.05$ was carried out. Polynomial regression analysis was conducted using SA concentrations data versus morpho-anatomical and non-choice preference data. The model that verified the 
highest value of the determination coefficient $\left(R^{2}\right)$ was chosen. Optimal concentration was estimated from the maximum or minimum point of the quadratic model from model derivation. The frequency data obtained from the choice tests were analysed by chi-square $\left(\chi^{2}\right)$ test $(p \leq 0.05)$, in which 1:1 was the null hypothesis assumed if TSSM had no preference for one treatment. Correlation among variables was accessed through Pearson's correlation ( $p \leq 0.05)$. Besides, a principal component analysis (PCA) was also performed. Statistical analysis was performed through software R (https://www.r-project.org/) using the packages 'graph' (Epskamp et al., 2012), 'easyanova' (Epskamp et al., 2012) and 'ggplot2' (Wickham, 2019).

\section{RESULTS}

\section{Morpho-anatomical assessments}

In general, all strawberry morpho-anatomical characteristics were affected by the application of SA at $p<0.01$ (Figures 3 and 4). Leaflet morpho-anatomy features as affected by SA concentrations through polynomial regression analysis are shown in Figure 3.
All the evaluated traits showed quadratic adjustment in the regression analyses ( $R^{2}$ from 0.72 to 0.95 ).

The maximum number of glandular (20.97) and nonglandular (28.41) trichomes per sample $\left(300 \mu \mathrm{m}^{2}\right)$ was estimated at $70.00 \mathrm{mg} \cdot \mathrm{L}^{-1}$ and $56.98 \mathrm{mg} \cdot \mathrm{L}^{-1}$ of $\mathrm{SA}$, respectively, with the lowest densities being observed in the control treatment $\left(0 \mathrm{mg} \cdot \mathrm{L}^{-1}\right)$ and the highest concentration $\left(100 \mathrm{mg} \cdot \mathrm{L}^{-1}\right)$ as shown in Figure 5. The maximum thickness of leaflets $(180.37 \mu \mathrm{m})$ and mesophyll $(125.52 \mu \mathrm{m})$ was estimated at $63.79 \mathrm{mg} \cdot \mathrm{L}^{-1}$ and $54.03 \mathrm{mg} \cdot \mathrm{L}^{-1}$ of SA, respectively. Also, the highest values for abaxial cell wall $(49.57 \mu \mathrm{m})$, adaxial cell wall $(48.27 \mu \mathrm{m})$, palisade parenchyma $(81.06 \mu \mathrm{m})$ and lacunous parenchyma $(56.12 \mu \mathrm{m})$ were observed from $52.96 \mathrm{mg} \cdot \mathrm{L}^{-1}$ and $71.16 \mathrm{mg} \cdot \mathrm{L}^{-1}$ of SA.

\section{Two-choice bioassay}

The observed frequencies in the two-choice assay were significant at $p<0.05$ when comparisons were achieved at concentrations of $25,50 \mathrm{or} 75 \mathrm{mg} \cdot \mathrm{L}^{-1}$ of SA compared with the control (Figure 4). Lack of significance was found at $100 \mathrm{mg} \cdot \mathrm{L}^{-1}$ when compared with the check treatment $(p<0.05)$, promoting an antagonistic effect. Normally, SA produces - as a defence response - a

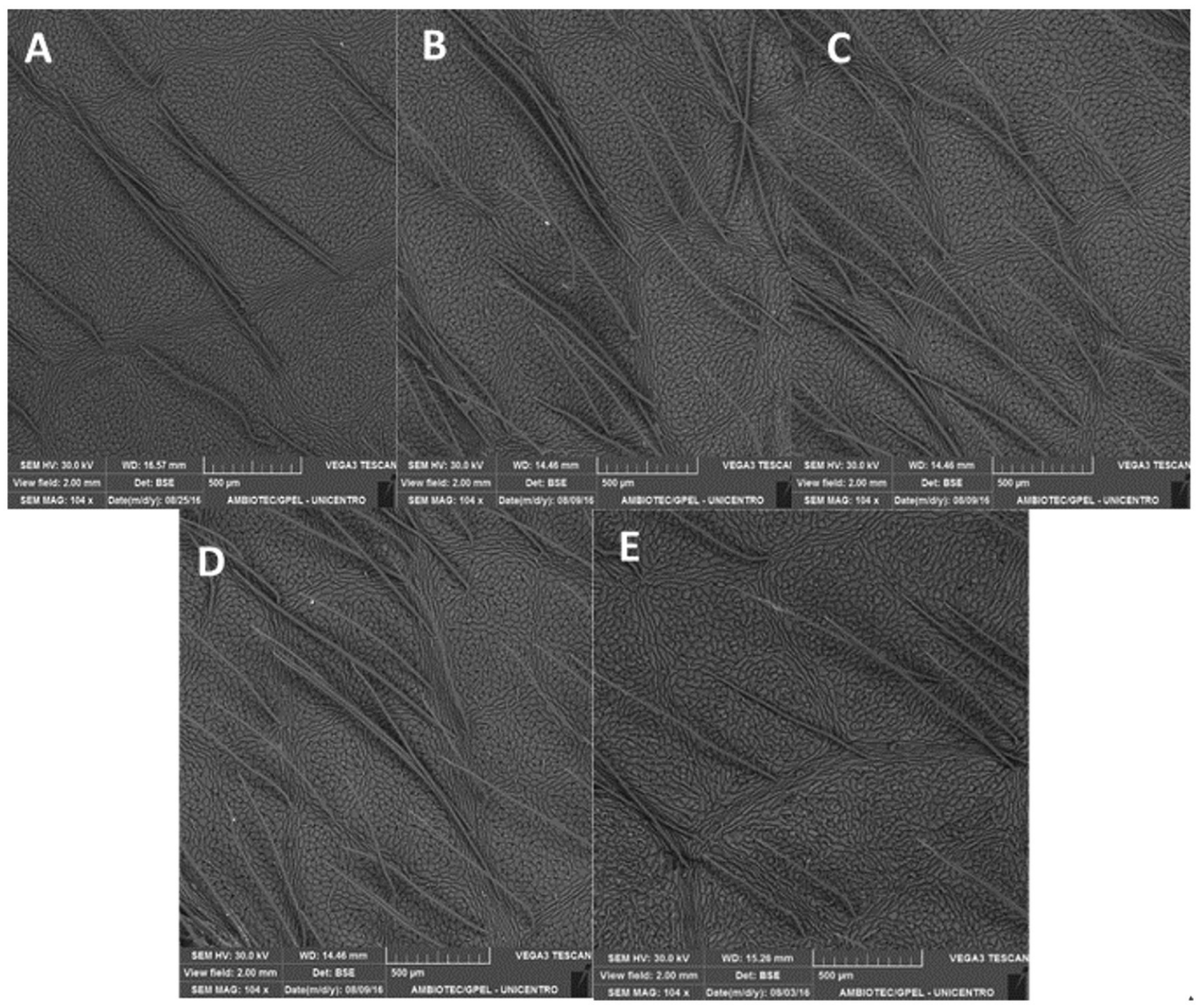

Figure 3. Density of non-glandular trichomes in strawberry leaflets of the cultivar 'Sweet Charlie' arranged on the abaxial surface, treated with doses of salicylic acid: (A) control; (B) $25 \mathrm{mg} \cdot \mathrm{L}^{-1}$; (C) $50 \mathrm{mg} \cdot \mathrm{L}^{-1}$; (D) $75 \mathrm{mg} \cdot \mathrm{L}^{-1}$ and (E) $100 \mathrm{mg} \cdot \mathrm{L}^{-1}$. 

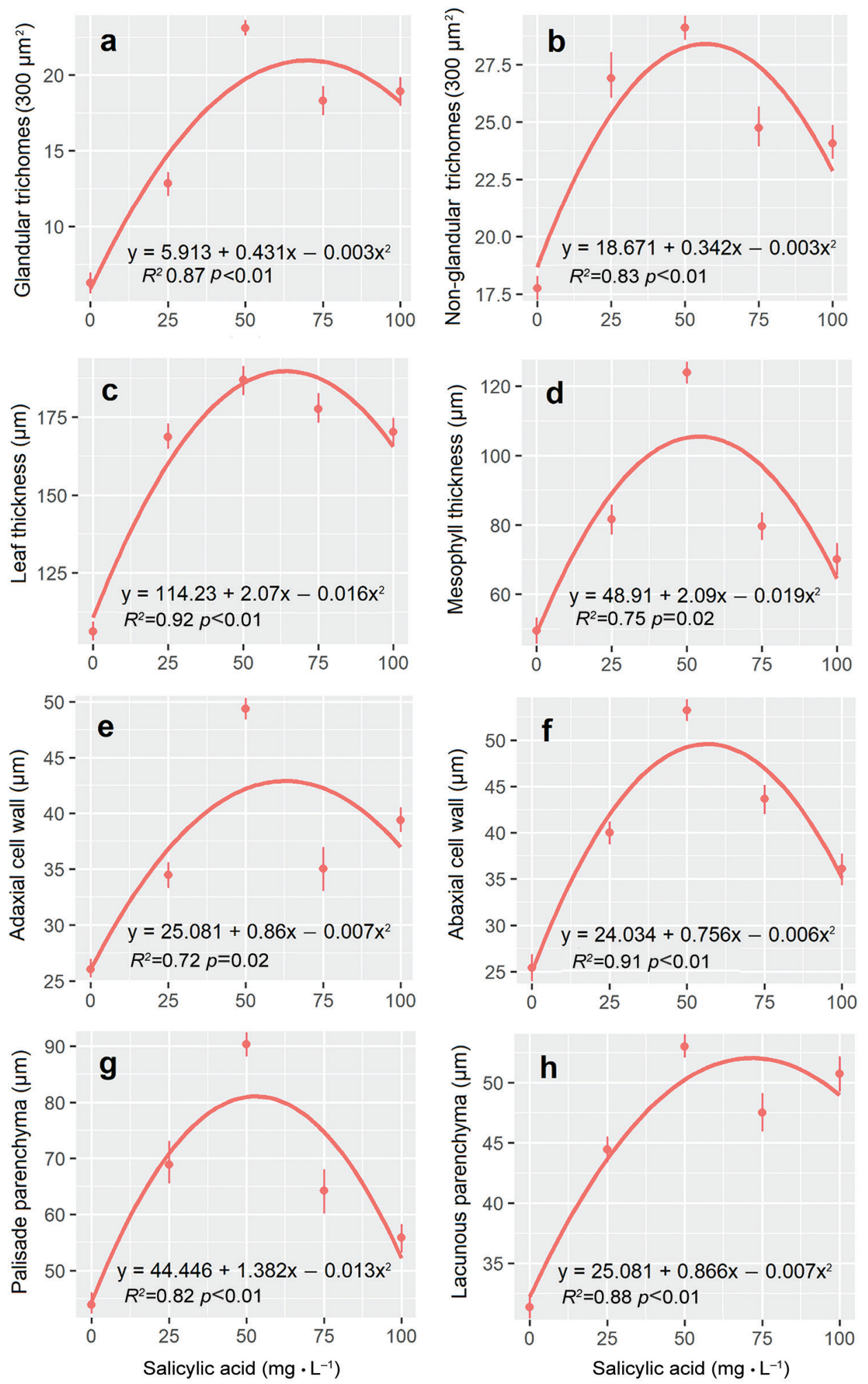

Figure 4. Morpho-anatomical traits of strawberry cv. 'Sweet Charlie' leaflets from plants treated with exogenous salicylic acid: (A) number to glandular trichomes; (B) number of non-glandular trichomes; (C) leaflet thickness; (D) mesophyll thickness; (E) adaxial epidermis thickness; (F) abaxial epidermis thickness; (G) palisade parenchyma thickness and $(\mathrm{H})$ lacunous parenchyma thickness. Numbers in $300 \mu \mathrm{m}^{2}$.

high concentration of peroxides, in addition to causing an imbalance in jasmonate. Overall, in the twochoice assay, TSSM females preferred leaflets from control plants than those treated with exogenous SA
(25 mg $\cdot \mathrm{L}^{-1}, 50 \mathrm{mg} \cdot \mathrm{L}^{-1}$ and $75 \mathrm{mg} \cdot \mathrm{L}^{-1}$ ), as shown in Figure 6. Similar numbers of TSSM were noted in leaflets from plants treated with $100 \mathrm{mg} \cdot \mathrm{L}^{-1}$ and checktreatment. 


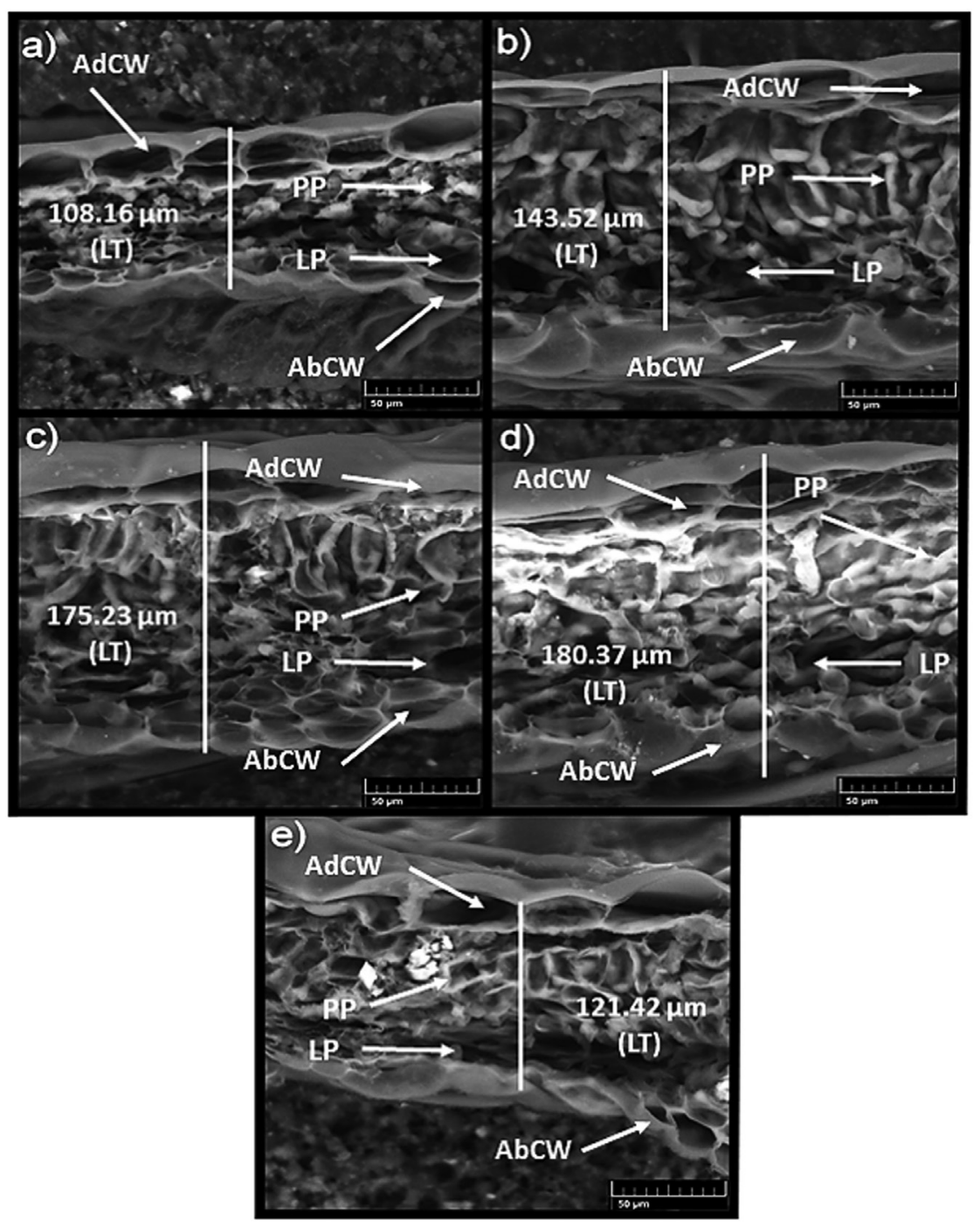

Figure 5. Morpho-anatomical changes in leaflets of strawberry cv. 'Sweet Charlie' from plants treated with exogenous salicylic acid concentrations: (A) $0 \mathrm{mg} \cdot \mathrm{L}^{-1}$, (B) $25 \mathrm{mg} \cdot \mathrm{L}^{-1}$, (C) $50 \mathrm{mg} \cdot \mathrm{L}^{-1}$, (D) $75 \mathrm{mg} \cdot \mathrm{L}^{-1}$ and (E) $100 \mathrm{mg} \cdot \mathrm{L}^{-1}$. Numeric values indicate leaflet thickness (LT) and arrows indicate the characteristics of palisade parenchyma thickness (PP), lacunous parenchyma thickness (LP), thickness of the abaxial cell wall (AbCW) and thickness of the adaxial cell wall $(\mathrm{AdCW})$.

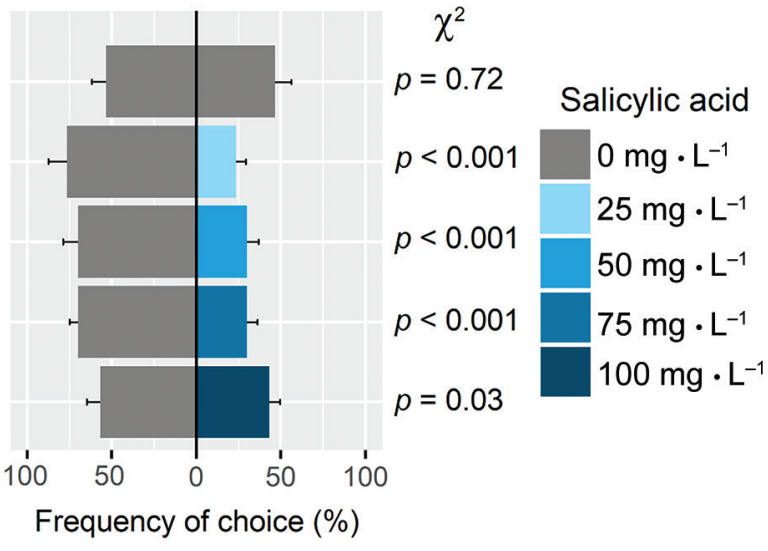

Figure 6. Responses of Tetranychus urticae to foliar disks of strawberry cv. 'Sweet Charlie' (control versus $25 \mathrm{mg} \cdot \mathrm{L}^{-1}, 50 \mathrm{mg} \cdot \mathrm{L}^{-1}, 75 \mathrm{mg} \cdot \mathrm{L}^{-1}$ and $100 \mathrm{mg} \cdot \mathrm{L}^{-1}$ of salicylic acid) in the two-choice Petri dishes assay.

\section{No-choice bioassay}

The variable number of live females and laid eggs fit the quadratic adjustment in the regression equations in function of the SA concentrations (Figure 7). A maximum reduction in the number of live females $\left(1.11\right.$ per $\left.\mathrm{mm}^{2}\right)$ was found for SA at $54.38 \mathrm{mg} \cdot \mathrm{L}^{-1}$. The smallest number of eggs (7.41 per $\left.\mathrm{mm}^{2}\right)$ was recorded at $54.88 \mathrm{mg} \cdot \mathrm{L}^{-1} \mathrm{SA}$.

\section{Correlation and PCA}

The TSSM number of laid eggs and live females was correlated negatively with the morpho-anatomic traits (Figure 8). Also, the number of laid eggs was strongly negatively correlated with palisade parenchyma, and adaxial and abaxial cell wall thickness. A moderate strong correlation between the number of laid eggs and the glandular and non-glandular trichomes was also found. The number of live females was strongly 

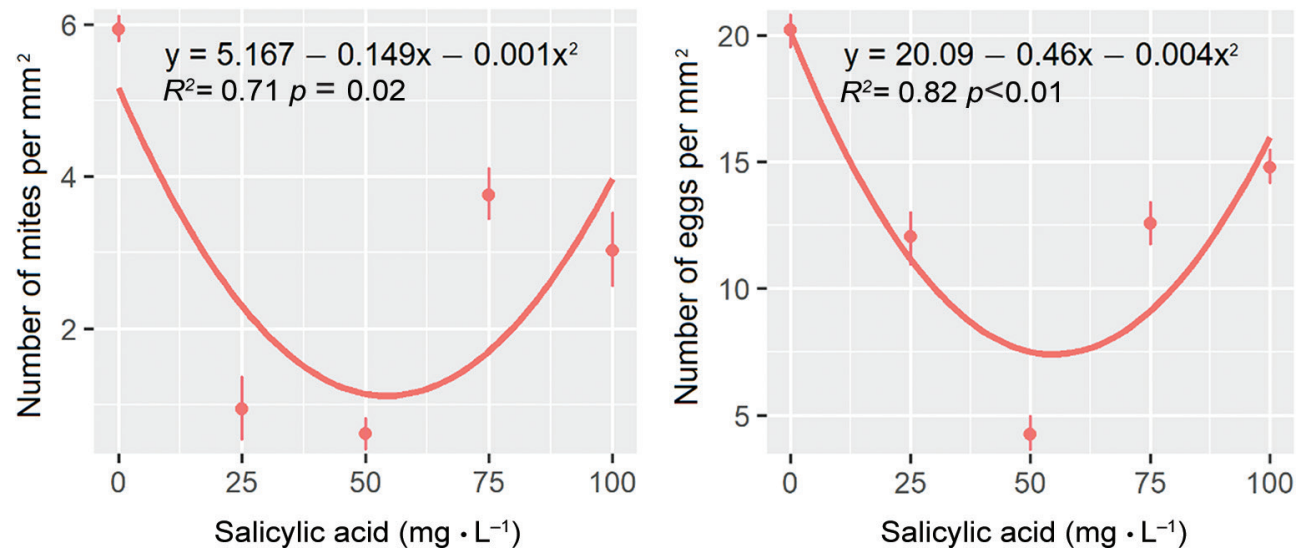

Figure 7. Number of eggs and live females of Tetranychus urticae per $\mathrm{mm}^{2}$ in foliar disks of strawberry cv. Sweet Charlie treated with concentrations of 0 (control), $25 \mathrm{mg} \cdot \mathrm{L}^{-1}, 50 \mathrm{mg} \cdot \mathrm{L}^{-1}, 75 \mathrm{mg} \cdot \mathrm{L}^{-1}$ and $100 \mathrm{mg} \cdot \mathrm{L}^{-1}$ of salicylic acid.

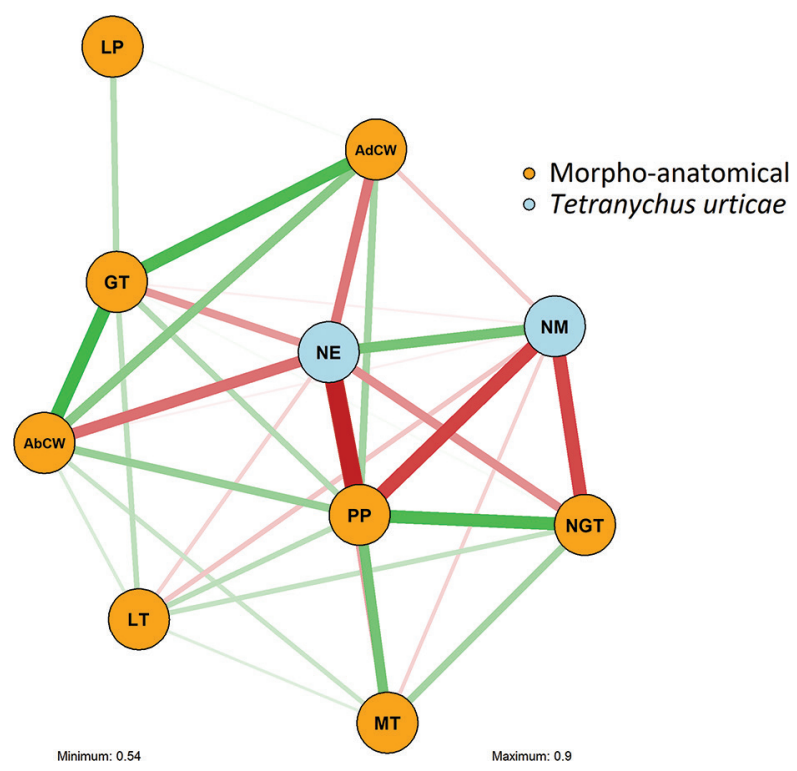

Figure 8. Correlation network among variables: leaflet thickness (LT), mesophyll thickness (MT), palisade parenchyma thickness (PP), lacunous parenchyma thickness (LP), abaxial cell wall thickness (AbCW), adaxial cell wall thickness (AdCW), number of glandular trichomes (GT), number of non-glandular trichomes (NGT), number of eggs (NE) and number of live females (NM). Red and green lines indicate positive and negative correlations, respectively, significant at $5 \%$ by $t$-student test. Line thickness is proportional to the correlation magnitude.

negatively correlated with the palisade parenchyma thickness and the number of glandular and non-glandular trichomes. Moreover, the thickness of the adaxial cell wall, mesophyll and leaflet were moderately correlated with the number of live females.

The first and second principal components ( $\mathrm{PC} 1$ and PC2) explained $65.8 \%$ and $11.1 \%$ of the total variation, respectively (Figure 9). From the PCA biplot, it is possible to observe that the vectors of characteristics MT, NGT, PP, LT, LP, AbCW, AdCW and GT were associated with the $50 \mathrm{~mL} \cdot \mathrm{L}^{-1}$ concentration, indicating that the highest averages of these characteristics were obtained in this SA concentration. However, the vectors of characteristics NE and NM were associated with the $0 \mathrm{~mL} \cdot \mathrm{L}^{-1}$ concentration. In general, the PCA agreed with the results presented by regression and correlation analyses.

\section{DISCUSSION}

This study aimed to investigate the effect of exogenous SA on morpho-anatomical changes in strawberry leaves and induced resistance against $T$. urticae. The findings reported in this article evidence that exogenous application of SA markedly affects the morpho-anatomic traits in a dose-dependent manner in strawberry leaflets. The morpho-anatomical changes can be explained by the direct SA effects on cell division and expansion (Kumari et al., 2018; Lu et al., 2016). Intermediated concentrations were the most suited to promote these changes. The magnitude of the differences was $42.9 \%, 60.1 \%$, $41.19 \%, 43.20 \%, 45.10 \%, 48.00 \%, 66.30 \%$ and $33.3 \%$ times higher than the control for thickness of the leaflet, mesophyll, lacunous and palisade parenchyma, cell wall (abaxial and adaxial) and number of glandular and nonglandular trichomes, respectively. Previously, SA was reported to regulate lignin deposition (Gallego-Giraldo et al., 2011; Tenhaken, 2015; Zhu, 2016), triggering hardness and thickness of the secondary cell wall.

Increasing leaflet thickness, mesophyll, lacunous and palisade parenchyma suggests that SA may act to stimulate cytokinin for gene expression by producing enzymes via chlorophyll biosynthesis, chloroplasts and ribulose 1-5 biphosphate - Rubisco production (Cortleven and Schmulling, 2015; Vishwakarma et al., 2018). This enzyme is associated with $\mathrm{CO}_{2}$ fixation (Calvin cycle) producing glyceraldehyde 3-P (triose-P), pectin and lignin, which are deposited in 


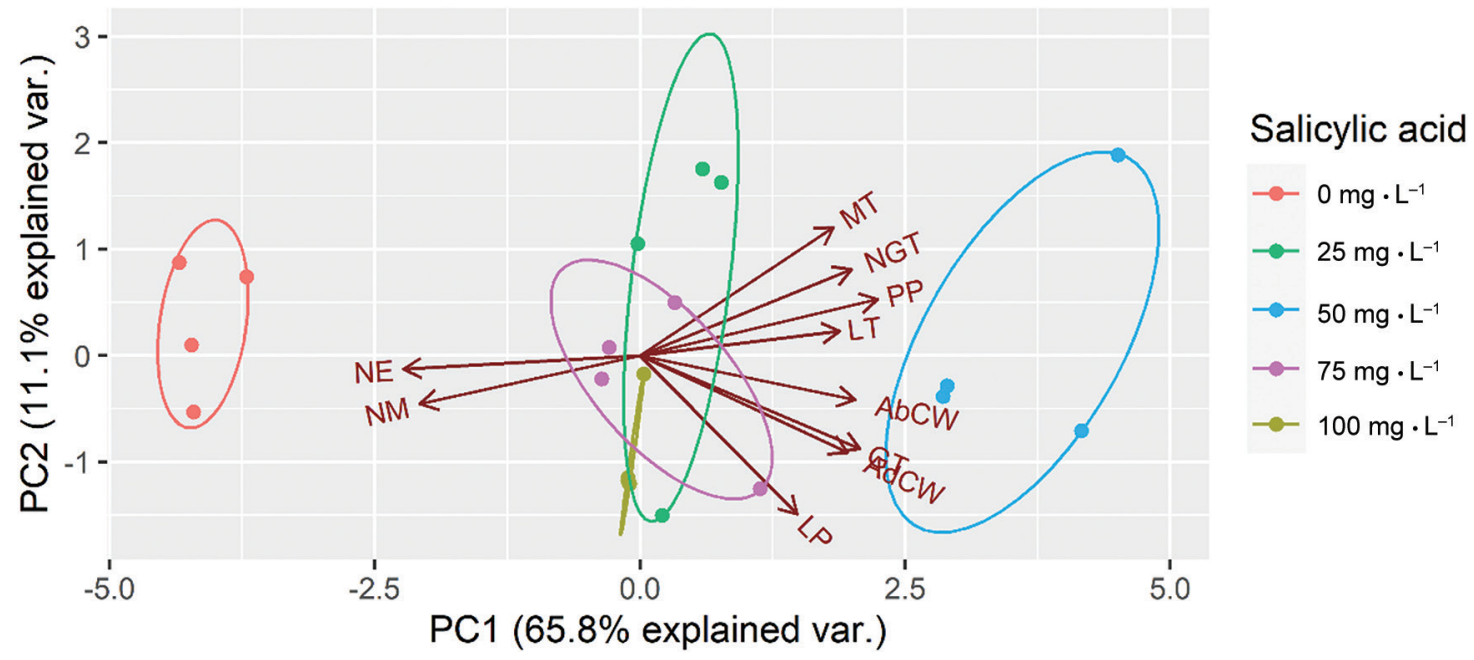

Figure 9. Principal component analysis (PCA) of salicylic acid concentrations evaluated for the variable leaflet thickness (LT), mesophyll thickness (MT), palisade parenchyma thickness (PP), lacunous parenchyma thickness (LP), abaxial cell wall thickness (AbCW), adaxial cell wall thickness (AdCW), number of glandular trichomes (GT), number of non-glandular trichomes (NGT), number of eggs (NE) and number of live females (NM).

the cell wall (Herrero et al., 2013; Ye et al., 2018) and possibly associated with plant resistance against biotic stresses (Baxter and Stewart, 2013). Thickness in morphological structures usually make it difficult to feed sucking pests such as mites and aphids. This fact is evidenced by the strong correlations estimated between mite survival and thickness of the parenchyma. It is inferred that the mite showed greater resistance to penetration from the cheliceras to the cleaved tubes. Inhibiting the penetration of the pest mouthpiece into cellular content is an important form of plant defence. Young larvae of Aphis fabae (Scopoli), Acyrthosiphon pisum (Harris) and Megoura viciae (Buckton) were unable to penetrate the cuticle of wild species of Vicia sp, thus not advancing to the next instar (Birch, 1984).

Regarding chickpeas plants, exogenous SA treatment increased the activity of glutamine synthetase, glutamate synthase and hydrogenase glutamate, suggesting stimulation of the nitrogen metabolism as shown previously. Subsequently, higher amino acids and proteins are synthesised to structure the plant morphology and anatomy, besides other functions (Birch, 1984; Conesa et al., 2020).

Increasing the number of glandular and nonglandular trichomes due to exogenous SA treatment agrees with other previous investigations on some plants such as tomato (Chen et al., 2018), Arabidopsis thaliana (Traw and Bergelson, 2013) and Artemisia annua (Kumari et al., 2018), which may confer resistance to pests (Aziz and Kapoor, 2018).

The current study showed that the highest SA concentrations diminished the magnitude of morphoanatomical changes in strawberry leaflets. Higher SA concentrations in tissues have been suggested as inhibiting gene transcription responsible for syntheses of structural proteins, mediated by jasmonic acid (Caarls et al., 2017) due to the antagonistic action of phytohormones (Ederli et al., 2020). Moreover, higher SA doses induce high levels of oxygen reactive species (ROS) and cause decreasing detoxification capacity, cell death and oxidative stress, which triggers an imbalance in physiological and biochemical plant activities (OtaizaGonzález et al., 2020).

Similarly, intermediate SA concentrations determined the highest change in TSSM responses in both two-choice and no-choice assays. Reduction in the number of eggs and live females in the no-choice assay reached $75 \%$ and $84.6 \%$ compared with the control, respectively. Treated strawberry plants with suitable SA concentrations may induce antixenosis and antibiosis on TSSM. Due to treatment with SA, the two-choice assay mites showed oviposition and permanence, in the test with a chance of choice, indicating that it is a resistance mechanism of the type antixenosis or no preference. The reduction in the number of eggs and live adult individuals on the surface of the leaflets with higher concentrations of SA application, in the test with no-choice, indicates that there was an influence of the treatment on the biology of the pest, and therefore, it is a mechanism of antibiosis resistance. Intermediate concentrations of SA were effective in reducing mite survival and oviposition in strawberry cultivars Aromas and Sweet Charlie, as observed in the present study (Favaro et al., 2019).

The influence of the strawberry foliar glandular and non-glandular trichomes on the resistance to TSSM was suggested by other researchers (Figueiredo et al., 2013; Kumari et al., 2018; Resende et al., 2020). Non-glandular trichomes function as a system of mechanical defence, diminishing oviposition, feeding and locomotion (Krimmel, 2014; Riddick and Simons, 2014), whereas glandular trichomes secrete and release 
defensive secondary metabolites such as terpenes, alkaloids and phenols (Delgoda and Murray, 2017; Tian et al., 2017). A significant and positive correlation between the trichome densities and TSSM infestation in strawberry cultivars was also previously noted (Esteca et al., 2017). The highest trichome density was found on 'IAC Princesa Isabel,' 'IAC T-0104,' and 'IAC 12' cultivars which were more resistant than 'IAC Guarani,' 'Oso Grande,' and 'Albion' (lesser trichome density) (Esteca et al., 2017). Glandular trichomes may also contain defensive substances that constitute a firstline chemical barrier against infesting arthropods. The sesquiterpenes Zingiberene, present in some tomato glandular trichomes, was associated with TSSM nymph mortality and diminishing fecundity (Oliveira et al., 2018; Oliveira et al., 2020). The strong correlation observed between the density of non-glandular trichomes and the oviposition and survival of adults are presumably related to the dysfunction caused by these structures to the movement and permanence of the mite on the surface of the leaflet (Resende et al., 2020).

Meanwhile, the thickness of the structures, as induced by proper SA concentration, may also constitute a barrier to TSSM and consequently reduce feeding, since before reaching the mesophyll, peripheral structures must be pierced and crossed by the stylet (Schmidt, 2014; Seki, 2016). Association between thicker foliar structure in barley (Hordeum vulgare L.) and diminishing TSSM feeding was observed previously due to disturbing stylet penetration into the leaf mesophyll (Gómes Sánches et al., 2018; Santamaria et al., 2020). A negative correlation between TSSM development and foliar thickness was also reported in melon plants (Cucumis melo L.) (Xu et al., 2019). Also, foliar thickness, mostly when associated with some biochemistry traits, was also associated with a reduction of Bemisia tabaci whitefly on egg plants, since negative correlations were observed for oviposition and the number of nymphs and adults (Khan et al., 2018).

The correlations indicate that the morphological characteristics directly interfered with the pest behaviour, decreasing oviposition and survival. The increase in the number of trichomes, glandular and nonglandular, correlated significantly and negatively with the oviposition and survival of the mites, as well as the thickness of the mesophilic abaxial surface and thickness of the palisade and lacunous parenchyma. The increase in non-glandular trichomes behaves like a physical barrier, making feeding and displacement on the surface difficult. Glandular trichomes release substances that repel or increase pest mortality (Antonious and Snyder, 2006). The ability to accumulate compounds such as terpenes and tannins (Rattan, 2010) and the production of oxidising enzymes involved in the oxidation and polymerisation of phenolic compounds, act as chemical barriers against the feeding of mites and indirectly affect their oviposition (Steinite and Ievinsh, 2003). To suck the plant's cellular liquid, the mite punctures the epidermis of the abaxial surface of strawberry leaves, causing cell damage (Fadini et al., 2007). The rupture of these cells results in the leakage of cell content, ending with cell death. Dead and injured cells cause physiological disorders, such as increased sweating rates and inhibition of starch synthesis in the chloroplast, resulting in the accumulation of starch precursors, such as D-glucose, in the cytoplasm. Thus, thicker morphoanatomical structures, such as parenchyma, cell wall and mesophyll, decrease the penetration of the oral apparatus of pests.

Regarding the mode of action, it is well known that SA is one of the modulators of systemic acquired resistance (SAR) on plants by activation of specific pathways that affect the gene expression and lead to the production of substances with a defensive proposal. In general, activation of the resistance modulated by SA on plants is possible since plants may detect abiotic and abiotic stressing factors (Yusuf et al., 2013) that trigger genetic, metabolomic and physiological changes. In the same vein, various secondary metabolite compounds may be produced by activation of the defence signalling pathways such as anthocyanin (Ran et al., 2013), rosmarinic acid (Sahu, 2013), terpenoids (Saiman et al., 2015) and flavonoids (Lee, 2010). A plethora of compounds are involved in TSSM plant resistance, as reviewed by Santamaria et al. (2020). SAR on plants mediated by exogenous SA may also cause increased production and release volatile repellents such as $\mathrm{MeSa}$ and $\delta$-limonene, which repel Bemisia tabaci biotype $\mathrm{B}$ on tomato plants (Shi et al., 2016) as a direct defense, attract natural enemies such as pests or even communicate with neighbourhood plants as an indirect defence (Rowen et al., 2017). The magnitude of the morpho-anatomical leaf changes on SA treated plants (Figures 3 and 4) suggests that, together with chemical changes, structural alterations may play a tiny role in SAR mediated by SA and deserve to be studied more deeply.

Using SA for TSSM management in strawberry crops may be tested in future studies due to the negative effects of treating plants with SA on TSSM preference and biology (Figures 4 and 6). SA could be applied when the environmental conditions - dry and warm weather - are favourable to TSSM development and could eventually be used together with other measures/ methods to minimise TSSM infestations such as biological control (Rowen et al., 2017) or intercropping systems (Hata et al., 2019). Under such conditions, strawberry flowering is also negatively affected. SA had been suggested as an activator of heat thermotolerance mechanisms (Hameed and Ali, 2016); further investigations could address these features.

\section{CONCLUSIONS}

Intermediate concentrations of SA promoted morphoanatomical changes in the strawberry leaf, increasing the thickness of the leaf structures and the number of 
glandular and non-glandular trichomes. There was a significant correlation between the SA doses and the resistance to the two-spotted spider mites, probably mediated by the morpho-anatomical changes in the leaves. The application of high doses of SA promotes an antagonistic effect, making the plant more susceptible.

\section{FUNDING}

This research was supported by the Program for Centers of Excellence (Pronex - FA/CNPq (PI) \#01/2018). R. M., D.Z.M, S.M.A and N.C.V.R are graduate students who participated with resources from the following research funding agencies: Coordination for the Improvement of Higher Education Personnel and the National Council for Scientific and Technological Development (CAPES Finance; CNPq).

\section{AUTHOR CONTRIBUTIONS}

J.T.V.R. took charge of project administration and funding acquisition. R.M. dealt with the methodology, validation and original draft preparation. S.M.A, D.M.Z, and L.V.C. were responsible for the methodology and validation. K.Y. and M.U.V. performed review and editing. N.C.V.R and J.T.V.R. were responsible for formal analyses, review, editing and funding acquisition.

\section{CONFLICT OF INTEREST}

Authors declare no conflict of interest.

\section{REFERENCES}

Antonious, G. F., And Snyder, J. C. (2006). Repellency and toxicity of wild tomato leaf extracts to twospotted spider mite, Tetranychus urticae Koch. Journal of Environmental Science and Health, 41, 43-55.

AzIz, A., AND Kapoor, D. (2018). Salicylic acid: It's physiological role and interactions. Research Journal of Pharmacy and Technology, 11, 3171-3177.

Backer, R., Naidoo, S., and Van den berg, N. (2019). The non expressor of pathogenesis-related gene 1 (NPR1) and related family: Mechanistic insights in plant disease resistance. Frontiers in Plant Science, 10, 1-21, doi:10.3389/fpls.2019.00102.

Baxter, H. L., and Stewart, C. N. (2013). Effects of altered lignin biosynthesis on phenylpropanoid metabolism and plant stress. Biofuels, 4, 635-650.

BIRCH, N. (1984). Resistance of three species of aphids in wild relatives of the faba bean (genus Vicia): Taxonomic patterns and possible mechanisms. IOBC-WPRS Bulletin, 7, 35-36.

Catrls, L., van Der Does, D., Hickman, R., Jansen, W., Verk, M. C., Proietti, S., Lorenzo, O., Solano, R., Pieterse, C. M., and van Wees, S. C. (2017).
Assessing the role of ethylene response factor transcriptional repressors in salicylic acid-mediated suppression of jasmonic acid-responsive genes. Plant \& Cell Physiology, 58, 266-278.

Chen, G., Klinkhamer, P. G. L., Escobar-bravo, R., AND LeISS, K. A. (2018). Type VI glandular trichome density and their derived volatiles are differently induced by jasmonic acid in developing and fully developed tomato leaves: Implications for thrips resistance. Plant Science, 276, 87-98.

Chen, Z., Zheng, Z., Huang, J., Lai, Z., and Fan, B. (2009). Biosynthesis of salicylic acid in plants. Plant Signaling \& Behavior 4, 493-496.

Conesa, C. M., Saez, A., Navarro-Neila, S., DE Lorenzo, L., Hunt, A. G., Sepúlveda, E. B., Baigorri, R., Garcia-Mina, J. M., Zamarreño, A. M., Sacristán, S., and Del Pozo, J. C. (2020). Alternative polyadenylation and salicylic acid modulate root responses to low nitrogen availability. Plants, 9, 251, doi:10.3390/plants9020251.

Cortleven, A., Schmulling, T. (2015). Regulation of chloroplast development and function by cytokinin. Journal of Experimental Botany, 66, 4999-5013.

Delgoda, R., and Murray, J. E. (2017). Evolutionary perspectives on the role of plant secondary metabolites. In S. Badal and R. Delgoda (Eds), Pharmacognosy: Fundamentals, applications and strategies (pp. 93-100). Cambridge, UK: Academic Press, Cambridge.

Dias, J. P. T., Filho, J. D., CARmo, E. L., Simões, J. C., AND PÁduA, J. G. (2012). Population fluctuation of spider mite Tetranychus urticae in different production systems of strawberry. Acta Horticulturae, 926, 625-630.

Donovan, M. P., Nabity, P. D., and Delucia, E. H. (2013). Salicylic acid-mediated reductions in yield in Nicotiana attenuata challenged by aphid herbivory. Arthropod-Plant Interactions, 7, 45-52.

Ederli, L., Salerno, G., Biachet, C., Rebora, M., Piersanti, S., And Pasqualini, S. (2020). Eurydema oleracea negatively affects defenses in Arabidopsis by inducing salicylic acid-mediated signaling pathway. Arthropod-Plant Interactions, 14, 139-148.

El-WaKeIL, N. E. (2013). Botanical pesticides and their mode of action. Gesunde Pflanzen, 65, 125-149.

Epskamp, S., Cramer, A. O. J., Waldorp, L. J., Schmittmann, V. D., And Borsboom, D. (2012). qgraph: Network visualizations of relationships in psychometric sata. Journal of Statistical Software, 48(4), 1-18.

Esteca, F. D. C. N., Dainese, C. D. N., Rodrigues, L. R., Lourenção, A. L., Passos, F. A., and Moraes, G. J. DE. (2017). Resistance of new strawberry genotypes to the two-spotted spider mite (Acari: Tetranychidae). Journal of Agricultural Science, 9, 119.

Fadini, M. A. M., Oliveira, H. G., Venzon, M., Pallini, A., AND Vilela, E. F. (2007). Spatial distribution 
of phytophagous mites (Acari: Tetranychidae) in strawberry. Neotropical Entomology, 36, 783-789.

Faostat (2020). Strawberry. Retrieved from http://www. fao.org/faostat/en/\#data/QC (accessed 21 July, 2020).

Favaro, R., Resende, J. T. V., Gabriel, A., Zeist, A. R., Cordeiro, E. C. N., and Favaro Júnior, J. L. (2019). Salicylic acid: Resistance inducer to twospotted spider mite in strawberry crop. Horticultura Brasileira, 37, 60-64.

Figueiredo, A. S. T., Resende, J. T. V., Morales, R. G. F., Gonçalves, A. P. S., DA SILVA, P. R. (2013). The role of glandular and non-glandular trichomes in the negative interactions between strawberry cultivars and spider mite. Arthropod-Plant Interactions, $7,53-58$.

Gallego-Giraldo, L., Escamilla-Trevino, L., Jackson, L.A., AND Dixon, R. A. (2011). Salicylic acid mediates the reduced growth of lignin down-regulated plants. Proceedings of the National Academy of Sciences, 108, 20814-20819.

Goldstein, J. I., Newbury, D. E., Echil, P., Joy, D. C., Romig JR, A. D., Lyman, C. E., Fiori, C., And Lidshin, E. (1992). Scanning electron microscopy and X-ray microanalysis. New York, USA: Plenum Press.

Gómez Sánchez, A., Gonzalez-Melendi, P., Santamaria, M. E., Arbona, V., Lopez-Gonzalvez, A., Garcia, A., Hensel, G., Kumlehn J., Manuel, M., And Isabel, D. (2018). Knock-downs for drought-induced cysteineprotease genes alter barley leaf structure and the response to abiotic and biotic stresses. Journal of Experimental Botany, 70(7), 2143-2155.

Hameed, S., And Ali, M. K. (2016). Exogenous application of salicylic acid: Inducing thermotolerance in cotton (Gossypium hirsutum L.) seedlings. International Journal of Agricultural and Food Research, 5, 9-18.

Hata, F. T., Ventura, M. U., De Souza, M. S. De J., De Sousa, N. V., OliveirA, B. G., Da Silva, J. B. (2019). Mineral and organic fertilization affects Tetranychus urticae, pseudo fruit production and leaf nutrient content in strawberry. Phytoparasitica, 47, 513-521.

Hayat, S., Irfan, M., Wani, A. S., Alyemeni, M. N., And Ahmad, A. (2012). Salicylic acids: Local, systemic or inter-systemic regulators? Plant Signaling \& Behavior, 7, 93-102.

Hayat, S., Ahmad, A., Wani, A. S., Alyemeni, M. N., AND Ahmad, A. (2014). Regulation of growth and photosynthetic parameters by salicylic acid and calcium in Brassica juncea under cadmium stress. Journal of Biosciences, 69, 452-458.

Herrero, J., Esteban-Carrasco, A., and Zapata, J. M. (2013). Looking for Arabidopsis thaliana peroxidases involved in lignin biosynthesis. Plant Physiology and Biochemistry, 67, 77-86.

Lachiab, N., Sanzani, S. M., Fallanaj, F., Youssef, K., Nigro, F., Boselli, M., and Ippolito, A. (2015). Protein hydrolysates as resistance inducers for controlling green mould of citrus fruit. Acta Horticulturae, 1065, 1593-1598.
Khan, M. M., Khan, M. Y., Muhammad, R., Ullah, K., Yasir, M., Khalid, A., And Khan, M. A. (2018). Morphological and biochemical characters of eggplant (Solanum melongena) conferring resistance against whitefly (Bemisia tabaci). Journal of Entomology and Zoology Studies, 6, 915-920.

Косн, S., Epp, A., Lohmann, M., And BöL, G. F. (2017). Pesticide residues in food: Attitudes, beliefs, and misconceptions among conventional and organic consumers. Journal of Food Protection, 80, 2083-2089.

Krimmel, B. A. (2014). Why plant trichomes might be better than we think for predatory insects. Pest Management Science, 70, 1666-1667.

Kumari, A., Pandey, N., and Pandey-Rai, S. (2018). Exogenous salicylic acid-mediated modulation of arsenic stress tolerance with enhanced accumulation of secondary metabolites and improved size of glandular trichomes in Artemisia annua L. Protoplasma, 255, 139-152.

LEE, J. C. (2010). Effect of methyl salicylate-based lures on beneficial and pest arthropods in strawberry. Environmental Entomology, 39, 653-660.

Lu, H., Greenberg, J. T., And Holuigue, L. (2016). Editorial: Salicylic acid signaling networks. Frontiers in Plant Science, 7, 1-3, doi:10.3389/ fpls.2016.00238.

Lucini, T., Faria, M. V., Rohde, C., Resende, J. T. V., and De Oliveira, J. R. F. (2015). Acylsugar and the role of trichomes in tomato genotypes resistance to Tetranychus urticae. Arthropod-Plant Interactions, 9, 45-53.

Miller, R. N. G., Alves, G. S. C., And van Sluys, M. A. (2017). Plant immunity: Unravelling the complexity of plant responses to biotic stresses. Annals of Botany, 119, 681-687.

Nazar, R., Iqbal, N., and Umar, S. (2017). Heat stress tolerance in plants: Action of salicylic acid. In R. Nazar, N. Iqbal, and N. A. Khan (Eds), Salicylic acid: A multifaceted hormone (pp. 145-161). Singapore: Springer.

Oliveira, J. R. F., Resende, J. T. V., Filho, R. B. L., Roberto, S. R., Silva, P. R., Rech, C., Nardi, C. (2020). Tomato breeding for sustainable crop systems: High levels of zingiberene providing resistance to multiple arthropods. Horticulturae, 6, 34, doi:10.3390/horticulturae6020034.

Oliveira, J. R. F., Resende, J. T. V., Maluf, W. R., Lucini, T., De Lima Filho, R. B., De Lima, I. P., And NARDI, C. (2018). Trichomes and allelochemicals in tomato genotypes have antagonistic effects upon behavior and biology of Tetranychus urticae. Frontiers in Plant Science, 9, 1-9, doi:10.3389/ fpls.2018.01132.

Ong, Y. J., Chen, J. C., Zhu, L., CaO, L. J., Jin, G. H., Hoffmann, A. A., Zhong, C. F., Wang, P., Lin, G., AND WeI, W. J.(2018). Preference and performance of the two-spotted spider mite Tetranychus 
urticae (Acari: Tetranychidae) on strawberry cultivars. Experimental and Applied Acarology, 76, 185-196.

Osman, M. E, Aboelnasr, A. A., Nawar, M. A., And Hefnawy, G. A. (2019). Myco-metabolites as biological control agents against the two-spotted spider mite, Tetranychus urticae Koch (Acari: Tetranychidae). Egyptian Journal of Biological Pest Control, 29, 64, doi:10.1186/s41938-019-0166-0.

Otaiza-González, S. N., Mary, V. S., Arias, S. L., Bertrand, L., Velez, P. A., Rodriguez, M. G., Rubinstein, H. R., And Theumer, M. G. (2020). Different salicylic and jasmonic acids imbalances are involved in the oxidative stress-mediated cell death, induced by fumonisin B1 in maize seedlings with contrasting resistance to Fusarium verticillioides ear rot in the field. BioRxiv, doi: 10.1101/2019.12.25.882597.

Ram, M., Prasad, K. V., Singh, S. K., Hada, B. S., And Kumar, S. (2013). Influence of salicylic acid and methyl jasmonate elicitation on anthocyanin production in callus cultures of Rosa hybrida L. Plant Cell, Tissue and Organ Culture, 113, 459-467.

Rattan, R. S. (2010). Mechanism of action of insecticidal secondary metabolites of plant origin. Crop Protection, 29, 913-920.

Resende, J. T. V., De Lima Filho, R. B., Ribeiro, L. K., Corrêa, J. V. W., De Goes Maciel, C. D., And Youssef, K. (2020). Strawberry genotypes with resistance to Tetranychus urticae mediated by leaf trichomes. Ciência e Agrotecnologia, 44, e006920, doi:10.1590/1413-7054202044006920.

Rezaie, M., Saboori, A., Baniamerie, V., Allahyari, H. (2013). Susceptibility of Tetranychus uticae Koch (Acari: Tetranychidae) on seven strawberry cultivars. International Research Journal of Applied and Basic Sciences, 4, 2455-2463.

Riddick, E. W., And Simmons, A. M. (2014). Do plant trichomes cause more harm than good to predatory insects? Pest Management Science, 70, 1655-1665.

Rowen, E., Gutensohn, M., Dudareva, N., and Kaplan, I. (2017). Carnivore attractant or plant elicitor? Multifunctional roles of methyl salicylate lures in tomato defense. Journal of Chemical Ecology, 43, 573-585.

Sahu, G. K. (2013). Salicylic acid: Role in plant physiology and stress tolerance. In G. R. Rout and A. B. Das (Eds), Molecular stress physiology of plants New York, USA: Springer, 217-239.

Saiman, M. Z., Mustafa, N. R., Choi, Y. H., Verpoorte, R., AND Schulte, A. E. (2015). Metabolic alterations and distribution of five-carbon precursors in jasmonic acid-elicited Catharanthus roseus cell suspension cultures. Plant Cell, Tissue and Organ Culture, 122, 351-362.

Santamaria, M. E., Arnaiz, A., Rosa-Diaz, I., GonzÁlez-Melendi, P., Romero-Hernandez, G.,
Ojeda-Martinez, D. A., Garcia, A., Contreras, E., Martinez, M., AND Diaz, I. (2020). Plant defenses against Tetranychus urticae: Mind the gaps. Plants, 9, 464, doi:10.3390/plants9040464.

Schmidt, R. A. (2014). Leaf structures affect predatory mites (Acari: Phytoseiidae) and biological control: A review. Experimental and Applied Acarology, $62,1-17$.

SEKI, K. (2016). Leaf-morphology-assisted selection for resistance to two-spotted spider mite Tetranychus urticae Koch (Acari: Tetranychidae) in carnations (Dianthus caryophyllus L). Pest Management Science, 72, 1926-1933.

Shi, X., Chen, G., Tian, L., Peng, Z., Xie, W., Wu, Q., Wang, S., Zhou, X., and Zhang, Y. (2016). The salicylic acid-mediated release of plant volatiles affects the host choice of Bemisia tabaci. International Journal of Molecular Science, 17, 1048, doi:10.3390/ijms 17071048.

Silva, V., Mol, H. G. J., Zomer, P., Tienstra, M., Ritsema, C. J., and Geissen, V. (2019). Pesticide residues in European agricultural soils - A hidden reality unfolded. Science of the Total Environment, $653,1532-1545$.

Steinite, I., And Ievinsh, G. (2003). Possible role of trichomes in the resistance of strawberry cultivars against spider mites. Acta Universitatis Latviensis. 662, 59-65.

Tenhaken, R. (2015). Cell wall remodeling under abiotic stress. Frontiers in Plant Science, 5, 771, doi:10.3389/fpls.2014.00771.

Tian, N., Liu, F., Wang, P., Zhang, X., Li, X., And Wu, G. (2017). The molecular basis of glandular trichome development and secondary metabolism in plants. Plant Gene, 12, 1-12.

Traw, M. B., And Bergelson, J. (2003). Interactive effects of jasmonic acid, salicylic acid, and gibberellin on induction of trichomes in Arabidopsis. Plant Physiology 133, 1367-1375.

Vishwakarma, S. K., Singh, R., Singh, P., and Kewat, R. N. (2018). Periodical evaluation of enzymes and pigments in mango varieties during storage in card board carton by post harvest application of salicylic acid. Journal of Pharmacognosy and Phytochemistry, SP2, 238-242.

WANG, Z., CANG, T., Wu, S., Wang, X., QI, P., WANG, X., And Zhao, X. (2018). Screening for suitable chemical acaricides against two-spotted spider mites, Tetranychus urticae, on greenhouse strawberries in China. Ecotoxicology and Environmental Safety, 163, 63-68.

Wani, A. B., Chadar, H., Wani, A. H., Singh, S., And Upadhyay, N. (2017). Salicylic acid to decrease plant stress. Environmental Chemistry Letters VOLUME, 15, 101-123.

Wickнам, H. (2019). Ggplot2 package. Create elegant data visualizations using the grammar of graphics. 
Xu, D., Wang, K., Zhang, Y., Wang, H., Wu, Q., And WAng, S. (2019). The performance of Tetranychus urticae on five melon cultivars is correlated with leaf thickness. Systematic and Applied Acarology, 24, 645-658.

Ye, D., Kiemle, S. N., Sintu, R., Wang, X., Wang, C., Cosgrove, D. J. Gomez, E. W., And Gomez, E. D. (2018). Resonant soft X-ray scattering reveals cellulose microfibril spacing in plant primary cell walls. Scientific Reports, 8, 12449, doi:10.1038/ s41598-018-31024-1.

Youssef, K., Roberto, S. R., AND De Oliveira, A. G. (2019). Ultra-structural alterations in
Botrytis cinerea - THE causal agent of gray moldtreated with salt solutions. Biomolecules, 9(10), 582, doi: 10.3390/biom9100582.

Yusuf, M., Hayat, S., Alyemeni, M., Fariduddin, Q., AND Ahmad, A. (2013). Salicylic acid: Physiological roles in plants. In S. Hayat, A. Ahmad and M. Alyemeni (Eds), Salicylic acid (pp. 15-30). Dordrecht: Springer.

ZHU, J. K. (2016). Abiotic stress signaling and responses in plants. Cell, 167, 313-324.

Received: October 14, 2020; accepted: March 3, 2021 